\title{
Detection of Trichomonas vaginalis in prostate tissue and serostatus in patients with asymptomatic benign prostatic hyperplasia
}

Jamshaid Iqbal ${ }^{1 *}$, Jumanah Al-Rashed ${ }^{1}$ and Elijah O. Kehinde ${ }^{2}$

\begin{abstract}
Background: Despite a worldwide common and progressive nature of benign prostate hyperplasia (BPH) in older men, no association has been observed between a causative pathogen and other etiology so far.

Methods: In this study, we investigated a causative association of Trichomonas vaginalis, a flagellate protozoan parasite, in $171 \mathrm{BPH}$ cases presenting without symptoms of prostatitis at a surgical outpatient clinic in Kuwait. We detected $T$. vaginalis DNA by polymerase chain reaction (PCR) and T. vaginalis antigen by immunocytochemistry (ICC) in the prostate tissue of these cases. A total of 171 age-matched controls with no urinary tract symptoms were also included in the study. A detailed information regarding the sexual history and sexually transmitted infections (STIS) was enquired from all the enrolled subjects.

Results: We detected T. vaginalis DNA and T. vaginalis antigen in 42 (24.6\%) and 37 (21.6\%) of the 171 BPH cases respectively in their prostate tissue. Both these assays showed a very good agreement and statistically no significant difference in their sensitivities and specificities. A relatively higher seropositivity rate for antibodies to $T$. vaginalis was detected in BPH cases (53 of 171 cases, $31.0 \%$ ) than in the control group (26.9 \%) [p: 0.19] and both were higher than in earlier reports but no significant association was observed between BPH and T. vaginalis serostatus. However, a greater proportion of seroreactive BPH cases had high IgG2 antibody absorbance score than in the control group (p:0.000). Furthermore, no significant association was observed between $T$. vaginalis seropositivity and presence of T. vaginalis DNA in the prostate tissue.

Conclusions: Our study documents T. vaginalis DNA and T. vaginalis antigen in 24.6 and $21.6 \%$ respectively in the prostate tissue of the BPH cases. We also detected a relatively higher seropositivity rate for antibodies to $T$. vaginalis both in the BPH cases and in normal control group, 31 and $26.9 \%$ respectively but no significant association was observed between BPH and T. vaginalis serostatus or presence of T. vaginalis DNA in the prostate tissue. Further epidemiological and case-controlled studies are needed to focus on local response to chronic asymptomatic retention of $T$. vaginalis in prostate tissue in the development of benign prostate hyperplasia.
\end{abstract}

Keywords: Benign prostate hyperplasia, Trichomonas vaginalis, Prostate tissue, Serostatus

\footnotetext{
* Correspondence: iqbal@hsc.edu.kw

'Department of Medical Microbiology, Faculty of Medicine, Kuwait University,

PO Box: 24923, Safat 13110, Kuwait

Full list of author information is available at the end of the article
} 


\section{Background}

Benign prostatic hyperplasia (BPH) and prostate cancer (PCa) represent the most common urologic diseases among the elderly males resulting in more than 2 million visits per year; $8 \%$ of the total urologic visits and $1 \%$ of family physician visits in the USA [1-3]. Its prevalence among men at risk is believed to be between 5 and $8 \%[4,5]$. BPH and $\mathrm{PCa}$ are considered chronic diseases, with early initiation and slow progression. Despite extensive research, the pathophysiology of $\mathrm{BPH}$ and $\mathrm{PCa}$ is not yet completely understood however, several observational and case-control studies have documented the role of sexually transmitted infections (STIs) in chronic inflammation as an important factor in $\mathrm{BPH}$ development and progression [6-8]. Several sexually transmitted agents such as Neisseria gonorrhoeae, Chlamydia trachomatis and Trichomonas vaginalis (T. vaginalis) are known to cause chronic inflammation within the prostate gland's tissue [9]. However, a recent large retrospective and prospective study did not support associations of several known STIs with BPH with the exception of $T$. vaginalis infection that showed modest association with $\mathrm{BPH}[10]$. T. vaginalis is a common parasitic sexually transmitted infection, with an estimated 174 million annual infections globally. Studies have shown that $T$. vaginalis can be associated with asymptomatic infections in 50-75\% of infected men and a number of observations support an association between $T$. vaginalis and prostatitis [11, 12]. As such, chronic prostatic infection with $T$. vaginalis may initiate an inflammatory response that could increase the risk of developing $\mathrm{BPH}$ and $\mathrm{PCa}$. The objective of the present study was to investigate the potential association between $T$. vaginalis infection and $\mathrm{BPH}$ by detecting $T$. vaginalis DNA and antigen in the prostate tissue and $T$. vaginalis serostatus in patients with $\mathrm{BPH}$ without clinical symptoms of prostatitis.

\section{Methods}

\section{Patient selection}

A total of $177 \mathrm{BPH}$ cases aged $>60$ years of age without clinical symptoms of prostatitis reporting at the Urological Clinic, Mubarak Al-Kabir Teaching Hospital, Kuwait were registered and treated for $\mathrm{BPH}$ by transurethral resection of the prostate (TURP) during the period June 2013December 2014. All enrolled cases were given a code number to preserve their confidentiality. From each of the enrolled cases, 5-6 small biopsy specimens were taken from the prostate for histopathology routine examination to confirm the diagnosis of $\mathrm{BPH}$ and $5 \mathrm{ml}$. blood to assess $T$. vaginalis serostatus. The biopsy specimens were also processed to detect $T$. vaginalis DNA and antigen in the tissue. The tissue was also processed to detect other relevant bacterial and viral pathogens by multiplex PCR and culture. A detailed information regarding the sexual history and sexually transmitted infections (STIs) was enquired from all the enrolled subjects. When available, their hospital records were also screened for this information.

We also included 177 control subjects from the same population group who had provided blood at the outpatient clinic for conditions other than prostate and/or urinary tract infection. For statistical efficiency, control subjects were individually matched to $\mathrm{BPH}$ cases by age.

\section{Polymerase chain reaction (PCR) for detection of $T$. vaginalis DNA in prostate tissue}

For detection of $T$. vaginalis, the prostate tissue was processed and the DNA extracted as described earlier [13, 14]. Briefly, the tissue samples were cultured in TYI S 33 medium with $10 \%$ bovine serum albumin at $37{ }^{\circ} \mathrm{C}$ for four days under anerobic conditions. The presence of $T$. vaginalis parasite was confirmed by light microscopy of the pellet after centrifugation of the culture supernatant. T. vaginalis-specific PCR was performed directly on the prostate tissue specimens and the DNA was extracted using QIAamp DNA Mini kit (Qiagen) following manufacturer's instructions. A set of primers targeting a conserved region of the beta-tubulin genes of $T$. vaginalis (btub1-2, and -3) was used for amplification; for BTUB 9: 5' CAT TGA TAA CGA AGC TCT TTA CGA T 3' (positions 850-874), and for BTUB 2: 5' GCA TGT TGT GCC GGA CAT AAC CAT 3' (positions 961-938) [13, 14]. The performance of beta-tubulin primers BTUB9 and BTUB2 was earlier evaluated in a pilot study to screen pregnant women for STDs including $T$. vaginalis at the maternity clinic in Kuwait during 2012-2013 using a series of positive controls.

A positive (ATCC 30236) and a negative (distilled water) control was used with each run. The DNA was amplified by PCR using an automated thermocycler (Perkin-Elmer Cetus, Norwalk, Conn.) using the standard final PCR reaction mixture $(50 \mu \mathrm{l})$. A single predicted $112 \mathrm{bp}$ PCR product was visualized on a $2 \%$ agarose gel stained with ethidium bromide. All PCR positives were confirmed by sequence analysis of the BTUB PCR product using a 3100-Avant Genetic analyzer (Applied Biosciences) and comparing data with Genebank as reported earlier [14].

\section{Immunocytochemistry (ICC) of fixed prostate tissue to detect Trichomonas vaginalis parasite antigen (TV Ag)}

The fresh biopsies were fixed in formalin, processed and embedded in paraffin wax and a 4-5 $\mu \mathrm{m}$ sections were cut. Staining was done after deparaffinization and rehydration by graded alcohols. Endogenous peroxidase activity was blocked using $0.3 \%$ hydrogen peroxide in Tris-buffered saline. For antigen retrieval the sections were treated with $10 \mathrm{mmol} / \mathrm{l}$ citrate buffer ( $\mathrm{pH}$ 6.1) in microwave for $5 \mathrm{~min}$ and then incubated with the mouse primary monoclonal anti-Trichomonas vaginalis antibody (MYBioSource, San 
Diego, USA). Avidin-biotin complex (ABC) method was used for antigens visualization. Briefly, EnVision Flex Dual Link horseradish peroxidase/DAB visualization system (Dako) was used and counterstained with haematoxylin. The specimen was considered positive if either nuclear only staining or nuclear and cytoplasmic staining was present. Positive control slides with Trichomonas vaginalis parasites were used for each run of samples.

\section{Detection of $T$. vaginalis serostatus}

T. vaginalis antibody serostatus (IgG, IgG subtypes) was measured by using an in-house indirect ELISA that detects antibodies against purified, recombinant $\alpha$-actinin protein from $T$. vaginalis parasite (strain $\mathrm{C}-1: \mathrm{NIH}$ ) as described earlier [15] with slight modifications. Briefly, the recombinant $\alpha$-actinin protein was purified from the harvested Escherichia coli colony containing the recombinant plasmid wit $\alpha$-actinin gene. Optimum dilution of the recombinant protein, serum and antihuman conjugates used in ELISA to screen for serostatus were determined by a checker-board titration. A panel of five known positive specimens from confirmed $T$. vaginalis cases and negative pooled specimens from uninfected individuals were used in random order with each run of the assay to determine absorbance score. Briefly, $100 \mu \mathrm{l}$ of paired plasma samples from the cases and controls diluted at 1:200 in phosphate-buffered-salineTween 20 containing $5 \%$ skim milk was added into microtiter wells coated with recombinant $\alpha$-actinin protein overnight. All specimen were used in duplicate in optimum dilutions as determined above (IgG; 1:200, IgG subtypes; 1:40) and inferences were based on the mean of duplicate values. The horseradish peroxidase-labelled antihuman IgG and the biotin-labelled antihuman IgG1/IgG2/IgG3/IgG4 (Sigma, St. Louis, MO, USA) were used at the calculated optimum dilution in PBS-Tween 20-BSA. The working dilution of HRP-labelled antihuman IgG was determined at $1: 5000$ and for IgG1/IgG2/IgG3/IgG4 at 1:1000, 1:5000, 1:2500 and 1:5000, respectively. The plates were incubated for $1 \mathrm{~h}$ at $37^{\circ} \mathrm{C}$ for $30 \mathrm{~min}$ followed by incubation with the substrate $\mathrm{H}_{2} \mathrm{O}_{2}$-OPD in citrate buffer. The reaction as stopped with $\mathrm{H}_{2} \mathrm{SO}_{4}$. The cut-off points for seropositivity were determined by obtaining positive to negative $(\mathrm{P} / \mathrm{N})$ ratios of the mean of duplicate optical densities (ODs) \pm 2 standard deviations (SD) values of the positive and negative control specimens as described earlier $[15,16]$. The absorbance score was then determined by comparing the $\mathrm{P} / \mathrm{N}$ values with ODs of the known positive control specimens. Samples with absorbance score of 1 with mean OD value of $>0.70$ were considered positive for $T$. vaginalis infection.

\section{Ethics statement}

The present study was reviewed and approved by the Faculty of Medicine, Kuwait University and Kuwait Institute for Medical Specialization (KIMS) joint Research Ethics
Committee. The Committee reviews experimental protocols involving human subjects and/or animal as per international standardized ethical guidelines. All patients gave their informed consent to their prostate tissue and blood sample for testing and they were informed of their studyrelated test results.

\section{Statistical analysis}

Statistical analysis were performed using SPSS 12.0.1 (SPSS Inc.). We used One way ANOVA and Post Hoc tests to analyze variables (total prostate specific antigen and antibody absorbance means, medians and proportions) by $t$ test using independent samples. The comparative performance of $T$. vaginalis antigen test and PCR assay was done by McNemar test. To explore potential associations of T. vaginalis serostatus and $\mathrm{BPH}$, we used conditional logistic regression to analyze potential $\mathrm{BPH}$ risk according to $T$. vaginalis antibody serostatus. Odds raios (ORs) and $95 \%$ confidence intervals (CIs) were estimated by comparing average optical density values and positive/negative values of $T$. vaginalis seropositive and -negative cases. Differences were considered significant with $p<0.05$.

\section{Results}

The prostate tissue from all $177 \mathrm{BPH}$ cases was processed for PCR analysis using a set of BTUB 9/2 primer set targeting a well-conserved region in the beta-tubulin genes of $T$. vaginalis (btub1-2, and -3) which amplified a single predicted 112 bp PCR product visualized on gel electrophoresis. We detected T. vaginalis DNA by PCR in 43 of $177(24.3 \%)$ cases. Six of the BPH cases who had characteristic $\mathrm{BPH}$ findings on routine histological examination were also shown to have additional incidental prostate cancer (iCaP), of which one was also positive for $T$. vaginalis DNA. The $\mathrm{iCaP}$ cases were removed from further testing and statistical analysis. Thus, $T$. vaginalis DNA was detected in 42 of 171 (24.6\%) BPH cases in prostate tissue specimens by PCR (Table 1). All PCR positives were confirmed by sequence analysis of the BTUB PCR product using a 3100-Avant Genetic analyzer and showed highest similarity to Btub1 (data not shown). The mean age of $\mathrm{BPH}$ cases positive for T. vaginalis DNA was 65.6 years $(\mathrm{SD}= \pm 5.3$ years $)$ and the DNA- negative cases was aged 65.8 years ( $\mathrm{SD}= \pm 2.3$ years) (Table 1 ).

The T. vaginalis culture was positive only in 6 of 171 tissue specimens. The $T$. vaginalis antigen in prostate tissue was detected by immunocytochemical (ICC) staining using purified primary monoclonal anti-Trichomonas vaginalis antibody. TV Ag assay was used to detect TV infection in the prostate tissue in this study in addition to TV-DNA test to evaluate its performance using TV-DNA test as the standard test. TV Ag was detected in 37 of 171 specimens (21.6\%); all of which were also positive for $T$. vaginalis DNA by PCR however, 5 of the PCR positive 
Table 1 Trichomonas vaginalis infection detection status by $\mathrm{PCR}$ and age of $\mathrm{BPH}$ patients

\begin{tabular}{|c|c|c|c|c|}
\hline \multirow[t]{2}{*}{ Diagnosis } & \multicolumn{2}{|c|}{ T. vaginalis positive (by $\mathrm{PCR}$ ) } & \multicolumn{2}{|c|}{ T. vaginalis negative (by PCR) } \\
\hline & $N(\%)$ & $\begin{array}{l}\text { Mean age } \pm \\
\text { SD }\end{array}$ & $N(\%)$ & $\begin{array}{l}\text { Mean age } \pm \\
\text { SD }\end{array}$ \\
\hline $\begin{array}{l}\mathrm{BPH} \text { and } \\
\mathrm{iCaP}\end{array}$ & $\begin{array}{l}43 / 177 \\
(24.3)\end{array}$ & $65.7 \pm 4.2$ & $\begin{array}{l}134 / 177 \\
(75.7)\end{array}$ & $65.8 \pm 5.1$ \\
\hline $\mathrm{BPH}$ only & $\begin{array}{l}42 / 171 \\
(24.6)\end{array}$ & $65.6 \pm 5.3$ & $\begin{array}{l}129 / 171 \\
(75.4)\end{array}$ & $65.8 \pm 2.3$ \\
\hline
\end{tabular}

$\mathrm{BPH}$ benign prostatic hyperplasia, $i \mathrm{CaP}$ incidental prostate cancer

specimens were negative for $T$. vaginalis antigen (Table 2). Using PCR for detection of $T$. vaginalis infection as the standard test, statistical analysis using McNemar test for Kappa agreement showed very good strength between the PCR and T. vaginalis antigen test and statistically no significant difference in their sensitivities (p: 0.25); antigen sensitivity: $89.29 \%, 95 \% \mathrm{CI}=71.77-97.73 \%$; antigen specificity: $100 \%, 95 \% \mathrm{CI}=95.85-100 \%$ ) (Table 2 ). No relevant co-infection of bacterial (syphilis, gonorrhea and chlamydia) and viral pathogens (herpes simplex virus and human papillomavirus) was detected in prostate tissue screened simultaneously for $T$. vaginalis by PCR (data not shown). A very limited information was available on the sexual history and STIs from all the enrolled cases and the controls and from their hospital records, where available. The mean age of our study group was $>65$ years and only $3 \mathrm{BPH}$ cases and 5 controls admitted having multiple sexual partners in the past but they claimed always practicing safe sex.

$T$. vaginalis antibody infection or serostatus was determined in all BPH cases and controls by detecting IgG and IgG subtype levels against purified recombinant $\alpha$ actinin proteins from $T$. vaginalis. The cut off values for seropositivity or $T$. vaginalis antibody infection was determined by obtaining $\mathrm{P} / \mathrm{N}$ ratios and absorbance score as described earlier in materials and methods. The cut off value for seropositive status was determined as mean OD value of 0.70 for the IgG. A total of 53 of 171 (31.0 \%) $\mathrm{BPH}$ cases and 46 of 171 (26.9\%) control cases were seropositive for T. vaginalis infection (p: 0.19; Table 3). In

Table 2 Comparative performance of T. vaginalis antigen test by immunocytochemistry assay and PCR assay to detect $\mathrm{T}$. vaginalis DNA in the prostate tissues from BPH cases

\begin{tabular}{lllll}
\hline & & PCR & & TOTAL \\
Ag. test & & + & - & \\
& + & 37 & 0 & 37 \\
& - & 5 & 129 & 134 \\
& TOTAL & 42 & 129 & 171 \\
\hline
\end{tabular}

Ag vs. PCR Kappa agreement: Value $=0.93 ; \mathrm{SE}=0.04 ; 95 \% \mathrm{Cl}=0.84-1.0$; Strength $=$ very good $\cdot$ McNemar test: $p$-value $=0.25$, not statistically significant difference in tests' sensitivities• antigen sensitivity: $89.29 \%, 95 \% \mathrm{Cl}=71.77-$ $97.73 \%$; antigen specificity: $100 \%, 95 \% \mathrm{Cl}=95.85-100 \%)$

SE standard error, $\mathrm{Cl}$ confidence interval general, $T$. vaginalis antibody mean absorbance values for IgGs were not significantly different in $\mathrm{BPH}$ or the control group, 0.569 vs 0.561 respectively (p:0.663; Table 3). However, a greater proportion of seroreactive BPH cases had high IgG2 subtype absorbance score than in the control group with the mean absorbance score of 0.202 vs 0.158 respectively (p:0.000; Table 3). Additional data on $\mathrm{BPH}$ PCR and seroreactivity of BPH and control cases and their statistical analysis is presented in the additional files. A summary of mean OD values of IgG and IgG sub-types in $\mathrm{BPH}$ and control cases is presented in Table 3.

\section{Discussion}

Despite a worldwide common and progressive nature of benign prostate hyperplasia in older men, no association has been observed between a causative pathogen and other etiology so far. In this study, we investigated a causative association of $T$. vaginalis in men $>65$ years of age with $\mathrm{BPH}$ by detecting $T$. vaginalis DNA and antigen in the prostate tissue of $\mathrm{BPH}$ cases presenting without symptoms of prostatitis at a surgical outpatient clinic in Kuwait. We detected $T$. vaginalis DNA and T. vaginalis antigen in 24.6 and $21.6 \%$ in the prostate tissue of the BPH cases respectively.

Although several previous case-control studies have observed positive associations between symptomatic STI, gonorrhea and syphilis and prostate cancer, the information on association of asymptomatic STI is limited and more so for BPH cases with the exception of $T$. vaginalis infection that showed modest association with $\mathrm{BPH}$ cases [14]. Our finding for T. vaginalis infection in $\mathrm{BPH}$ cases is consistent with earlier studies that reported a high prevalence of $T$. vaginalis DNA in prostate tissue (34 \%) from men who underwent TURP for BPH [14] and the urine of patients with chronic prostatitis (21.2 \%) [17]. The detection rate of T. vaginalis infection in men has been shown to vary according to geographical location, presence or absence of symptoms, age, presence or absence of $T$. vaginalis infection in sexual partners and diagnostic methods $[18,19]$. We used PCR assay with BTUB primer pair which is shown to have increased sensitivity and specificity $[14,19,20]$. The specificity of PCR data was further complemented by detection of $T$. vaginalis antigen in the prostate tissue with primary monoclonal anti-Trichomonas vaginalis antibody by immunocytochemistry assay. Both TV-DNA and TV Ag assays were used to measure TV infection. While TV-DNA test has been used in earlier studies to detect TV infection, we also included TV Ag assay in this study to evaluate its performance in detecting TV infection in the prostate tissue. Both these assays showed very good agreement and no statistically significant difference in their sensitivities and specificities (antigen sensitivity: 89.29, antigen specificity; $100 \%$; p:0.25). 
Table $3 \mathrm{~T}$. vaginalis a-actin lgG and lgG-subtype antibody levels in 171 benign prostate hyperplasia cases and the control group

\begin{tabular}{llll}
\hline & BPH cases & $\begin{array}{l}\text { Control } \\
\text { group }\end{array}$ & $p^{\text {a }}$ \\
\hline $\begin{array}{l}\text { T. vaginalis antibody serostatus. No. } \\
\text { (\%) }\end{array}$ & 53 & $49(28.7 \%)$ & 0.19 \\
Mean OD & $(31.0 \%)$ & & \\
$\quad$ Total IgGs & 0.569 & 0.561 & 0.663 \\
Median OD & & & \\
$\quad$ Total IgGs & 0.592 & 0.567 & \\
Mean OD & & & \\
IgG1 & 0.086 & 0.088 & 0.758 \\
IgG2 & 0.202 & 0.158 & $0.000^{\text {a }}$ \\
IgG3 & 0.159 & 0.153 & 0.374 \\
IgG4 & 0.113 & 0.112 & 0.936 \\
\hline a optical density & & &
\end{tabular}

In our study, the mean age of all registered cases was $65.6 \pm 5.3$ years but no information was available on the $T$. vaginalis infection status of their sexual partners. Very limited information regarding the sexual history and STIs was available from all the enrolled subjects. When available, their hospital records were also screened for this information. The Kuwaiti population is a very conservative society esp. with regards to extramarital sexual activities and as such, STI data registry is very limited at the STD clinics. The mean age of our study group was 65 years and as expected, only $3 \mathrm{BPH}$ cases and 5 controls admitted having multiple sexual partners in the past but they claimed always practicing safe sex. The most probable and common route of transmission is sexual however, since the majority of infections in men are asymptomatic and they don't take treatment when their sexual partners (spouses) are diagnosed with $T$. vaginalis so the men may be carrying this infection unnoticed. We suspect that these self-reported rates of trichomoniasis were likely underreported the true infection among the cases and controls because trichomoniasis is frequently asymptomatic and infrequently diagnosed in men seeking STI care. In addition, one of the selection criteria of our cases was $\mathrm{BPH}$ without clinical symptoms of prostatitis to rule out pathogenic and/or non-pathogenic acute infections. As such, T. vaginalis seroreactivity status was used to assess a history of trichomoniasis to establish a temporal relationship between trichomonal exposure and $\mathrm{BPH}$, and to detect asymptomatic infections that might otherwise not be registered by self-report.

Recently, exposure to environmental factors such as infectious agents, hormonal imbalances and dietary carcinogens were proposed to lead to injury of the prostate and to the development of chronic inflammation however, no such hypothesis was forwarded for BPH [19]. A relatively high detection rate of $T$. vaginalis DNA by PCR and trichomonas specific antigen by ICC in the prostate tissue of asymptomatic $\mathrm{BPH}$ cases in this report provides a strong direct evidence of intraprostatic $T$. vaginalis infection indicating chronic retention of this parasite in the prostate tissue, which may be linked to development of BPH. Recently, an in vitro evidence of inflammatory response of prostate epithelial cells to stimulation by $T$. vaginalis mediated by immune cells and cytokines supported the role of trichomonas in prostate hyperplasia [19].

In this study, the seropositivity for antibodies to $T$. vaginalis in $\mathrm{BPH}$ cases $(31.0 \%)$ and in the control group $(26.9 \%)$ was relatively higher in our study population than some of the earlier reports (p: 0.19) [16, 21]. A panel of five known seropositive and seronegative pooled specimens were included with each test run to determine the cut-off points and absorbance score for $T$. vaginalis infection. The differences in assay sensitivities and demographic characteristics may account for some of the variations in distribution of $T$. vaginalis seropositivity in these studies. In general, $T$. vaginalis antibody mean ODs for IgGs were not significantly different in $\mathrm{BPH}$ or the control group, 0.569 vs 0.561 respectively (p:0.663). However, a greater proportion of BPH cases had high IgG2 subtype OD values than in the control group with the mean ODs of 0.202 vs 0.158 respectively (p:0.000) which may be incidental and we don't have any explanation for its biological relevance. Furthermore, no significant association was observed between seroreactivity and $T$. vaginalis DNA status in the prostate tissue (p:0.259). A number of large nested case-control studies have observed a positive association between $T$. vaginalis antibody seropositivity and prostate cancer [16, 21-23] but very little is known on seroreactivity to $T$. vaginalis in $\mathrm{BPH}$ cases. Recently, in a large retrospective and prospective study most of the STIs did not contribute to $\mathrm{BPH}$ development but a modest association of T. vaginalis infection with nocturia and a large prostate volume was observed [10]. A number of reports documenting serum antitrichomonal antibodies in male and female patients with acute and chronic trichomoniasis [24], and the increase in the prevalence of $T$. vaginalis with age suggested the prostate to be the reservoir for $T$. vaginalis $[25,26]$.

\section{Conclusions}

In conclusion, we report an expected association of $T$. vaginalis infection in $\mathrm{BPH}$ cases by detecting $T$. vaginalis DNA and antigen in 24.6 and $21.6 \%$ respectively in the prostate tissue of the $\mathrm{BPH}$ cases not presenting with symptoms of prostatitis. The seroprevalence of $T$. vaginalis infection was $31.0 \%$ in $\mathrm{BPH}$ cases and $26.9 \%$ in the control subjects with no significant difference in 
their mean absorbance values or presence of $T$. vaginalis DNA in the prostate tissue. We also conclude from this study that a large proportion of the detected trichomonas infections in men were chronic, asymptomatic infections, which, without treatment, may have progressed to the prostate tissue causing chronic prostate infection. This would induce an inflammatory response in the normal prostate that may potentially lead to hyperproliferation of prostatic epithelial cells leading to BPH. Further epidemiological and case-controlled studies are needed to focus on local response to chronic asymptomatic retention of T. vaginalis in prostate tissue in the development of BPH.

\section{Additional file}

Additional file 1: Raw data and statistical analysis. All data generated or analyzed during this study on each individual benign prostate hyperplasia (BPH) and control case is presented. The data includes information on the following: -Levels of IgG subtypes (OD values), $-T$ vaginalis-PCR positive and negative cases (OD values), -All statistical data analyzed during this study on IgG subtypes among BPH and control subjects. (XLSX $39 \mathrm{~kb})$

\section{Abbreviations}

BPH: Benign prostate hyperplasia; ICC: Immunocytochemistry;

PCR: Polymerase chain reaction; T. vaginalis: Trichomonas vaginalis

\section{Acknowledgement}

The Financial support for the study was provided by the Research Sector, Kuwait University, Kuwait, project \# YM 03/12.

\section{Availability of data and materials}

All data generated or analyzed during this study are included in this published article [and its Additional file 1].

\begin{abstract}
Authors' contributions
$J$ made substantial contribution to the study concept, design and analysis and interpretation of data. JR contributed in the conduction of PCR and ICC assays to acquire data. EK was involved in the selection of patients and conducting trans-urethral resection of the prostate tissue and taking biopsy specimen. All authors read and approved the final manuscript.
\end{abstract}

\section{Competing interests}

The authors declare that they have no competing interests.

\section{Consent for publication}

Not applicable.

\section{Ethics approval and consent to participate}

The present study was reviewed and approved by the Faculty of Medicine, Kuwait University and Kuwait Institute for Medical Specialization (KIMS) joint Research Ethics Committee. The Committee reviews experimental protocols involving human subjects and/or animal as per international standardized ethical guidelines. All patients gave their informed consent to their prostate tissue and blood sample for testing and all patients were informed of their study-related test results.

\section{Author details}

'Department of Medical Microbiology, Faculty of Medicine, Kuwait University, PO Box: 24923, Safat 13110, Kuwait. ${ }^{2}$ Department of Surgery (Division of Urology), Faculty of Medicine, Kuwait University, PO Box: 24923, Safat 13110, Kuwait.
Received: 12 May 2016 Accepted: 17 September 2016

Published online: 23 September 2016

\section{References}

1. Sciarra A, Di Silverio F, Salciccia S, Autran AM, Gentilucci A, Gentile V. Inflammation and chronic prostatic diseases: evidence for a link? Eur Urol. 2007:52:964-72.

2. Alcaraz A, Hammerer P, Tubaro A, Schröder FH, Castro R. Is there evidence of a relationship between benign prostatic hyperplasia and prostate cancer? Findings of a literature review. Eur Urol. 2009;55:864-75.

3. Smith JD, Garber GE. Trichomonas vaginalis infection induces vaginal CD4 cell infiltration in a mouse model: A vaccine strategy to reduce vaginal infection and HIV transmission.J Infect Dis. 2015;212(2):285-93.

4. Kramer $\mathrm{G}$, Mitteregger $\mathrm{D}$, Marberger $\mathrm{M}$. Is benign prostatic hyperplasia (BPH) an immune inflammatory disease? Eur Urol. 2007:51:1202-16.

5. Jemal A, Siegel R, Xu J, Ward E. Cancer statistics. CA Cancer J Clin. 2010;60:277-300.

6. Joseph MA, Harlow SD, Wei JT, Sarma R, Taylor JMG, Cooney KA, Doerr KM, Montie JE, Schottenfeld D. Risk factors for lower urinary tract symptoms in a population-based sample of African-American men. Am J Epidemiol. 2003; 157(10):906-14.

7. Koo CL, Kok LF, Lee MY, Wu TS, Cheng YW, Hsu JD, Ruan A, Chao KC, Han CP. Scoring mechanisms of p16INK4a immunohistochemistry based on either independent nucleic stain or mixed cytoplasmic with nucleic expression can significantly signal to distinguish between endocervical and endometrial adenocarcinomas in a tissue microarray study. J Transl Med. 2009;7:25. doi:10.1186/1479-5876-7-25.

8. Mirka WJ, Agnieszka O, David JD, Esther E, Simon C, Rohit B. Immunohistochemistry and HPV in situ hybridization in pathologic distinction between endocervical and endometrial adenocarcinoma: a comparative tissue microarray study of 76 tumors. Int J Gynecol Cancer. 2013;23(2):380-4.

9. De Marzo AM, Platz EA, Sutcliffe S, Xu J, Gronberg H, Drake CG, Nakai Y, Isaacs WB, Nelson WG. Inflammation in prostate carcinogenesis. Nat Rev Cancer. 2007;7:256-69.

10. Breyer BN, Huang W-Y, Rabkin CS, Alderete JF, Pakpahan R, Beason TS, Kenfield SA, Mabie J, Ragard L, Wolin KY, Grubb III RL, Andriole GL, Sutcliffe S. Sexually transmitted infections, benign prostatic hyperplasia and lower urinary tract symptom related outcomes: results from the prostate, lung, colorectal and ovarian cancer screening trial. BJUI. 2016;117(1):145-54.

11. Gardner Jr WA, Culberson DE, Bennett BD. Trichomonas vaginalis in the prostate gland. Arch Pathol Lab Med. 1986;1 10:430-2.

12. Sena AC, Miller WC, Hobbs MM, Schwebke JR, Leone PA, Swygard H, Atashili J, Cohen MS. Trichomonas vaginalis infection in male sexual partners: implications for diagnosis, treatment, and prevention. Clin Infect Dis. 2007;44:13-22.

13. Madico G, Quinn TC, Rompalo A, McKee Jr KT, Gaydos CA. Diagnosis of Trichomonas vaginalis infection by PCR using vaginal swab samples. J Clin Microbiol. 1998:36:3205-10.

14. Mitteregger D, Aberle SW, Makristathis A, Walochnik J, Brozek W, Marberger M, Kramer $\mathrm{G}$. High detection rate of Trichomonas vaginalis in benign hyperplastic prostatic tissue. Med Microbiol Immunol. 2012;201:113-6.

15. Addis MF, Rappelli P, Delogu G, Carta F, Cappuccinelli P, Fiori PL. Cloning and molecular characterization of a CDNA clone coding for Trichomonas vaginalis $a-a c t i n i n$ and intracellular localization of the protein. Infect Immun. 1998:66:4924-31.

16. Stark JR, Judson G, Alderete JF, Mundodi V, Kucknoor AS, Giovannucci EL, Platz EA, Sutcliffe S, Katja Fall K, Kurth T, Jing M, Meir JM, Stampfer J, Mucci LA Prospective study of Trichomonas vaginalis infection and prostate cancer incidence and mortality: physicians' health study. J Natl Cancer Inst. 2009:101:1-6.

17. Lee JJ, Moon HS, Lee TY, Hwang HS, Ahn MH, Ryu JS. PCR for diagnosis of male Trichomonas vaginalis infection with chronic prostatitis and urethritis. Korean J Parasitol. 2012;50:157-9.

18. Skerk V, Schönwald S, Krhen I, Markovinović L, Beus A, Kuzmanović NS, Kruzić V, Vince A. Aetiology of chronic prostatitis. Int J Antimicrob Agents. 2002;19:471-4.

19. Seo MY, Im SJ, Gu NY, Kim JH, Chung YH, Ahn MH, Ryu JS. Inflammatory response of prostate epithelial cells to stimulation by Trichomonas vaginalis. Prostate. 2014;74(4):441-9.

20. Krieger JN, Riley DE, Roberts MC, Berger RE. Prokaryotic DNA sequences in patients with chronic idiopathic prostatitis. J Clin Microbiol. 1996;34(12):3120-8. 
21. Sutcliffe S, Giovannucci E, Alderete JF, Chang TH, Gaydos CA, Zenilman JM De Marzo AM, Willett WC, Platz EA. Plasma antibodies against Trichomonas vaginalis and subsequent risk of prostate cancer. Cancer Epidemiol Biomarkers Prev. 2006:15(5):939-45.

22. Kaur S, Khurana S, Bagga R, Wanchu A, Malla N. Antitrichomonas IgG, IgM, IgA, and lgG subclass responses in human intravaginal trichomoniasis. Parasitol Res. 2008;103:305-12.

23. Cogne M, Brasseur P, Ballet JJ. Detection and characterization of serum antitrichomonal antibodies in urogenital trichomoniasis. J Clin Microbiol. 1985;21:588-92.

24. Alderete JF, Newton E, Dennis C, Neale KA. Antibody in sera of patients infected with Trichomonas vaginalis is to trichomonad proteinases. Genitourin Med. 1991;67:331-4.

25. Bowden FJ, Paterson BA, Mein J, Savage J, Fairley CK, Garland SM, Tabrizi SN. Estimating the prevalence of Trichomonas vaginalis, Chlamydia trachomatis, Neisseria gonorrhoeae, and human papillomavirus infection in indigenous women in northern Australia. Sex Transm Infect. 1999;75:431-4.

26. Miller WC, Swygard H, Hobbs MM, Ford CA, Handcock MS, Morris M, Schmitz JL, Cohen MS, Harris KM, Udry JR. The prevalence of trichomoniasis in young adults in the United States. Sex Transm Dis. 2005;32:593-8.

Submit your next manuscript to BioMed Central and we will help you at every step:

- We accept pre-submission inquiries

- Our selector tool helps you to find the most relevant journal

- We provide round the clock customer support

- Convenient online submission

- Thorough peer review

- Inclusion in PubMed and all major indexing services

- Maximum visibility for your research

Submit your manuscript at www.biomedcentral.com/submit
Biomed Central 